\title{
Why Should We Learn to Swim?
}

\author{
Gabriel Miranda Nava* \\ Chief of Neurology of the Hospital Center of the Presidential General Staff, Mexico
}

*Corresponding author: Gabriel Miranda Nava, Chief of Neurology of the Hospital Center of the Presidential General Staff, Mexico.

Received Date: September 01, 2018

Published Date: November 26, 2018

\section{Opinion}

There is an anecdote in which an intellectual was being transported in a small boat by a person of scarce academic resources, when trying to mock this poor man he asks "young ... do you know? Of mathematics? And the poor boatman answers NO, and the unfriendly scholar tells him "because he thinks you've lost $30 \%$ of your life, later he asks him if he knew about philosophy and when he answered with a second refusal, the scholar in question tells him that he had he lost another $30 \%$ of his life, and he maintained it until suddenly the boatman, smiling, asked him, "Sir, do you? Can you swim? The intellectual in question responds, "naturally not" and the boatman ends up telling him "well, pretend that you lost $100 \%$ of your life because the ship sinks".

Every time I see a patient with tension headaches or spinal problems or even insomnia, an important point of recommendation is intense exercise, which is often not walking or doing the job, it is an appropriate athletic behavior with plan and an added diet, which if done to the letter would greatly reduce the problems of spine, metabolism, overweight and many more ; I always put swimming ahead of other sports that add to the rehabilitation due to a series of advantages that other sports activities do not have, such as:

$>$ Exercise in deadlifts and that they are not injured anymore by contact and spinal column or knees and even hips.

$>$ Improve your breathing, not least in patients with sleep problems or anxiety disorders.
$>$ Improves the paravertebral muscles, which are the main supporting muscles of the spine, balances them and allows the spine to regenerate; here it is important to point out that they do not serve the chiropractic, it is an aberration and they are not doctors.

$>\quad$ It allows you to better socialize and acquire better sports goals.

$>$ It is excellent for the heart, lungs and digestive disorders.

We can mention many advantages of swimming and it would be a very long list, but it goes without saying that the people who really start learning to swim and do it not only improve their health, but also manage to overcome a challenge that was saved in the chest of the defeats.

One more point: the only ones I have heard who do not recommend swimming are often physiotherapists, and sometimes I think it is because if people swim, they would be out of work.

\section{Acknowledgement}

None.

\section{Conflict of Interest}

Author declared no conflict of interest. 